\title{
A new natural detector for irradiations with blue LED light source in photodynamic therapy measurements via UV-Vis spectroscopy
}

\author{
Lucas N. de Oliveira $^{1,2}$ (1) $\cdot$ Eriberto O. do Nascimento ${ }^{1} \cdot$ Linda V. E. Caldas $^{2}$ \\ Received: 5 February 2021 / Accepted: 3 August 2021 / Published online: 30 September 2021 \\ (c) The Author(s), under exclusive licence to European Photochemistry Association, European Society for Photobiology 2021
}

\begin{abstract}
Photodynamic therapy has been recently studied, bringing innovations regarding the reduction of exposure time to light by the patient. This work aimed to investigate the feasibility of using Coutarea hexandra (Jacq.) K. Schum (CHS) as a detector in photodynamic therapy measurements. For this, an irradiator containing a blue LED bulb lamp was utilized. The CHS samples were irradiated with ten doses from 0.60 up to $6.0 \mathrm{~kJ} / \mathrm{cm}^{2}$, and six concentrations were prepared $(1,2,3,4,5$, and $6 \mathrm{mg} / \mathrm{ml}$ ) for the CHS detector samples. After irradiation, the detector samples were evaluated using UV-Vis spectrophotometry. The results showed the behavior of the CHS detector with doses and concentrations, its sensitivity, and its linearity was also evaluated both by Wavelength Method (WM) and the Kernel Principal Component Regression (KPCR) Statistical Method. The values obtained indicate that this method can be applied to the CHS sample detector. In conclusion, the CHS is a promising detector in the field of photodynamic therapy.
\end{abstract}

Keywords New natural detector $\cdot$ UV-Vis technique $\cdot$ Blue LED source light

\section{Introduction}

Photodynamic therapy (PDT) has been investigated recently [1-4] in studies about new drugs [5], using nanoparticles [6], control microbial biofilms [7], and applications in advanced nanomaterials [8]. PDT consists of the annihilation of several cancers, through an incident visible light (VL), which sensitizes a drug called photosensitizer (PS), causing damage to living tissue (cancer cells), occurring the production of oxygen in this process [9-11]. For more details on the molecular basis, photosensitizers in medicine, the reaction mechanism, and the various modifications in PDT can be found in the literature [12-18]. The photosensitizers most used in PDT are the drug families: Porphyrin, Chlorin and Dyes [19]. Photosensitizers in recent decades have undergone modifications [20] with the main objective of reducing

Lucas N. de Oliveira

lucas@ifg.edu.br

1 Instituto Federal de Educação, Ciência e Tecnologia de Goiás-IFG, Rua 75, 46, Campus Goiânia, Goiânia, GO 74055-110, Brazil

2 Instituto de Pesquisas Energéticas e Nucleares, Comissão Nacional de Energia Nuclear-IPEN/CNEN, Av. Prof. Lineu Prestes, 2242, São Paulo, SP 05508-000, Brazil concentrations and accumulation in the target areas of PS, not neglecting the effects on cancerous destruction. Some PS from plants have also been used in PDT with favorable results, such as Rubiadin and Soranjidiol [21], and Quinones [22].

In this context, this work focuses on the feasibility of a new photosensitizer to be used in PDT: the plant tested for its feasibility is Coutarea hexandra (Jacq.) K. Schum (CHS), that comes mainly from Brazil and appears in the states such as Amazonas (AM), Minas Gerais (MG), Pará (PA), extending to the state of São Paulo (SP). In each region, the quina popular name is modified and its applications according to the local population, being its use more common in antimalarial [23], antidiabetic, anti-contraceptive, and anti-inflammatory processes [24].

The PS feature can be performed using non-invasive and destructive techniques such as Ultraviolet-Visible spectrometry (UV-Vis) [25], which provides information on the absorbance as a function of the wavelength at which incident visible light sensitizes the PS.

Spectra from FTIR, and UV-Vis measurements, among others, can undergo pre-processing of their responses to be used in multivariate analysis [26-30]. This kind of analysis has been applied in several areas of knowledge to provide information, model, and to compare actual 
measurements with their prediction methods [31, 32]. A pre-processing method used is the Principal Component Analysis (PCA) method [33-36], which aims to resize the input data to a matrix containing the same information, but with a smaller size. This new information is associated with the number of components from the PCA called eigenvectors; usually, only two components are used for all the information described in the data system. After the PCA method, the other robust statistical methods can be applied [37, 38]. For the clustering analysis, it is necessary to apply k-means algorithm methods, consisting of partitioning the $n$ observations among $k$ groups. Each group is separated according to the distance of the values closest to their means (centroids). These separate groups are called clusters $[39,40]$.

In a physicochemical system under investigation that contains multiple degrees of freedom, e.g., several concentrations range and absorbed doses for a given sample, it is possible to apply the Kernel Principal Component Regression (KPCR) method to determine the possible linearity behavior of the system. KPCR is used to handle the multicollinearity effect among the independent variables from the regression data; this method has been used successfully for this objective [41-44].

This work aims to analyze, for the first time, the viability of CHS detector in PDT via UV-Vis measurements using multivariate statistical techniques such as PCA, k-means, and KPCR.

\section{Materials and methods}

\subsection{Equipment and preparation of the CHS detector}

The preparation of the CHS solution can be described in the schematic process as in phases a to f. In phase a, the CHS powder is measured on a semi-analytical balance; in phase $b$, there is the beaker containing $71.6 \mathrm{ml}$ of $70 \%$ ethyl alcohol, also there is a small handle containing $126.4 \mathrm{ml}$ of milli-Q water, and a vessel with $500 \mathrm{ml}$ of volume, containing the CHS powder; in phase $\mathrm{c}$, all reagents are added slowly to the vessel and mixed; in phase $\mathrm{d}$, the solution is added to a funnel, $10 \mathrm{~cm}$ in diameter which contains a $9 \mathrm{~cm}$ diameter filter, $44 \mu \mathrm{m}$ pore, $250 \mathrm{~g}$ weight, thickness of $0.5 \mathrm{~mm}$ connected to a $250 \mathrm{ml}$ beaker which houses the filtered solution; in phase e, the solution is transferred to a $500 \mathrm{ml}$ glass container, covered with aluminum foil, and kept in a refrigerator $\left(15^{\circ} \mathrm{C}\right)$ for $72 \mathrm{~h}$; in phase $\mathrm{f}$, the ready solution is inserted into standard cuvettes with dimensions of $1.0 \times 1.0 \times 4.5 \mathrm{~cm}^{3}$ through a micropipette, thus making the CHS detector samples. Altogether there were six concentrations which are: 1 , $2,3,4,5$, and $6 \mathrm{mg} / \mathrm{ml}$ for the CHS detector samples.

\subsection{Irradiations and evaluation of CHS detector samples}

The radiation source was a blue bulb with a wavelength around $440-485 \mathrm{~nm}$. This lamp was placed in front of the CHS samples ( $0.5 \mathrm{~cm}$ surface-source distance) and controlled by a circuit coupled to a microcontroller (Raspberry Computer Model B Pi 4 with 4 GB of RAM).

A program was developed in Matlab ${ }^{\circledR} 2020$ a, to turn the lamp on and off; more details of the irradiation system can be seen in the literature [4]. The irradiations were carried out in the laboratory in darkness with the only window closed and with a curtain, to prevent the entry of light from outside. In this environment, the temperature was controlled through an air conditioner turned on at $20{ }^{\circ} \mathrm{C}$ throughout the experiment.

The irradiation times were: $5,10,15,20,25,30,35$, 40,45 , and $50 \mathrm{~min}$, which correspond to the doses: 0.60 , $1.20,1.80,2.40,3.00,3.60,4.20,4.80,5.40$, and $6.00 \mathrm{~kJ} /$ $\mathrm{cm}^{2}$, respectively.

After irradiation, CHS samples were evaluated using the Genesys 10S/Thermo Scientific spectrophotometer, coupled to a UV-Vis Vision Life data system software.

\subsection{Parameters for CHS detector samples}

The absorbance of the CHS detector samples was determined by the Law of Lambert-Beer, which considers the logarithmic ratio between the non-irradiated samples and irradiated samples from the new detector. All the measurements were made in triplicate, and the average values are reported. Therefore, some characterization tests of the CHS detector samples can be performed regarding the determination of the CHS spectra for six concentrations and ten doses; calibration curves from six concentrations of CHS samples; the evaluation of the linearity considering the squared Pearson correlation coefficient $\left(R^{2}\right)$; the sensitivity; and results for statistical methods. The definitions of linearity, sensitivity and Wavelength Method (WM) for spectra obtained with the UV-Vis technique can be found in the literature [4].

\subsection{Multivariate dose-response analysis}

Multivariate analysis is a field of mathematics that deals with multidimensional matrices. As a result, linear algebra is coupled with statistics to produce tools that find regression relationships between multiple responses and their predictor variables, regardless of the data dimensions. Specifically, in radiation physics, multivariate analysis is 
used as a processing technique sinking to determine a parsimonious model that fits the data.

This work used a combination of analytical methods to ascertain how the absorbance readings vary as a function of the coupled effects of the CHS powder concentration and the absorbed dose. The characterization of the absorbance distribution over the effects of concentrations and absorbed dose is essential because it is possible to assess linear relationships among the absorbance reading and the concentration factor.

The applied method to the multivariate analysis was twofold: first to find similar patterns within the absorbance distribution according to their wavelength index, while pondering the effects of the concentration and simultaneously the absorbed dose through the k-means coupled with Principal Component Analysis (PCA); second, with the Kernel Principal Component Regression (KPCR) to fit a model and then characterize the possible linear behavior between the absorbance reading as a function of the absorbed dose and the concentration.

\subsection{1 k-means algorithm coupled with Principal Component Analysis (PCA)}

To find similar patterns within the absorbance distribution while pondering the effects of $(K=6)$ concentration varying from $1,2,3,4,5$ to $6 \mathrm{mg} / \mathrm{ml}$, and absorbed dose $(M=10)$ number of total doses, $0.60,1.20,1.80,2.40,3.00,3.60$, $4.20,4.80,5.40$, and $6.00 \mathrm{~kJ} / \mathrm{cm}^{2}$; taken in the discrete values $(N=150)$, the values of absorbance comprised between the region of wavelength from 400 to $550 \mathrm{~nm}$. One group corresponded to 150 samples of $R^{2}$; thus, the sample size was 150. In total, six groups from the effect of concentration ranging from 1 to $6 \mathrm{ml} / \mathrm{mg}$ were evaluated.

The k-means algorithm clustered the absorbance data, but since the readings' dimensions were high, the k-means was coupled with the PCA. Consequently, the spectral absorbance reading for all concentrations was projected into a lower dimension space using the PCA after clustered in a two-dimensional space.

Therefore, in the PCA [45-47] method, the data is first written in a condensed matrix form as $\left\{x_{i}\right\}_{i=1}^{N} \in \mathbb{R}^{N}$, which is equivalent to $x_{i}=\left(x_{i 1} x_{i 2} \cdots x_{i p}\right)^{T}$, where $x_{i}$ is the regression variable, and $x_{i j}$ corresponds to $i$ th observation $(i=1,2, \ldots, N)$, to the $j$ th $(j=1,2, \ldots, M)$ regression variables, defining the matrices $\tilde{X}=\left(x_{1} x_{2} \cdots x_{p}\right)^{T}$ and $X_{c}=\tilde{X}\left(I_{N}-N^{-1} 1_{N} 1_{N}^{\prime}\right)$. The zero mean-centered covariance matrix is written as:

$C=\frac{1}{M-1} X_{c}^{\prime} X_{c}$

where the term $(\cdot)^{T}$ denotes the transpose of the matrix; $(\cdot)^{-1}$ is the inverse of the matrix; $\tilde{X}$ is a global matrix which contents all elements; $X_{c}$ is the centered matrix of $\tilde{X} ; I_{N}$ is the identity matrix; $1_{N}$ is a matrix with all entries equal to 1 . The covariance matrix $C$ is related to the $\tilde{X}$ matrix through the eigenspaces as a canonical basis, with the columns being the eigenvector of the observations, i.e., the principal components. Applying the eigendecomposition in Eq. 1, the results are:

$C=V \Lambda V^{\prime}=\sum_{k=1}^{p} \lambda_{k} v_{k} v_{k}^{\prime}$,

where $C$ covariance matrix $C$ is related to the $\tilde{X}$. Such relation is made through the eigenspaces as the canonical basis; $V_{N \times N}$ is the matrix eigenvectors (orthogonal); $v_{k}$ are the eigenvalues from columns of the $V_{N \times N} ; \Lambda$ is spectral matrix; $\operatorname{diag}(\Lambda)$ are composed of the eigenvalues $\left(\lambda_{k} \cdots \lambda_{p}\right) ; s_{k k}$ is the diagonal of $S$, where $\lambda_{k}=s_{k k}^{2}$.

The first two components of $C$ correspond to the most significant variances in $\tilde{X}$, i.e., as a corollary, with the deflation of the number of principal components represented by the eigenvectors, the data variance is maintained at high levels according to the final number of eigenvectors and its magnitudes. Thus, with the two most significant eigenvalues and eigenvectors, the $\tilde{X}$ is projected into bi-dimensional space, which allowed the k-means to cluster the data into regions.

The cluster was set using as a decision rule the smallest Euclidean distance between the established regions $\mu_{j}$ centroids $(C)$ and the $\tilde{X}$ matrix data now standardized by z-score of the $C$ matrix, all of which come from the PCA, according to

$\left.\sum_{i=0}^{N} \min _{\mu_{j} \in C}\left\|C_{i}-\mu_{j}\right\|^{2}\right)$

New centroids were standardized by mean values, standard deviations, and $S$ matrix, all of which come from the PCA.

\subsubsection{Principal Kernel Component Regression-KPCR}

The first step in implementing the KPCR [44, 48] was to transform the $\tilde{X}$ matrix through a function $\psi: \mathbb{R}^{g} \rightarrow F$, where $F$ is the feature space is a Euclidean space of higher dimension than $g$, called $g_{F}$. The $\psi$ function is not explicitly defined but is obtained through $\kappa: \mathbb{R}^{g} \times \mathbb{R}^{g} \rightarrow \mathbb{R}$, where $\kappa$ is the Kernel function. The Kernel is defined as $\mathrm{K}=\Psi \Psi^{T}$ and $\Psi=\left(\psi\left(\tilde{x}_{1}\right) \psi\left(\tilde{x}_{2}\right) \cdots \psi\left(\tilde{x}_{N}\right)\right)^{T}$, the dimensions of $\Psi$ and $\mathrm{K}$ are $N \times g^{H}$ and $N \times N$, respectively.

The KPCR is fundamentally a Multiple Linear Regression (MLR) applied in the feature space $F$. The relationship between the feature space in the higher dimension and the Euclidean space is made through the Kernel trick. 
First, it was set the Kernel Gaussian as the mapping to the feature space, given as:

$k(x, y)=e^{-\left(\frac{\|x-y\|}{h}\right)}$.

Then, the MLR in the feature space is given as $Y=\Psi \eta+\epsilon^{\prime}$, and $\Psi$ the normalized eigenvectors $v_{i}$ of $\Psi^{T} \Psi$ is the correspondent of $V=\left(v_{1} v_{2} \cdots v_{g^{F}}\right)$ matrix, and $V V^{T}=I_{g^{F}}$, then the model above can be rewritten using the Kernel trick in the Reproducing Kernel Hilbert Space (RKHS):

$Y_{\circ}=B \omega+\varepsilon^{\prime}$.

In Eq. 5, the independent variable $Y$ originally in the Euclidean space should be centered by the mean values on the feature space. This process is made through Eq. 6:

$Y_{\circ}=\left(I_{N}-\frac{1}{N} 1_{N} 1_{N}^{T}\right) Y$,

where $B=\Psi V$ and $\omega=\left(\omega_{1} \omega_{2} \cdots \omega_{g^{F}}\right)^{T}=V^{T} \eta$, which is equivalent to the eigendecomposition problem, where $\widehat{\omega}=\left(\widehat{\omega}_{1} \widehat{\omega}_{2} \cdots \widehat{\omega}_{g^{F}}\right)^{T}$ is the estimator of $\omega$, which can be written as $\hat{\omega}=\left(B^{T} B\right)^{-1} B^{T} Y$.

$\eta=V \hat{\omega}=\sum_{i=1}^{p_{f}} \mu_{i}^{-1} v_{i} v_{i}^{T} \Psi^{T} Y$

It is noted that the dimension of $\widehat{\omega}$ depends on the number of principal components $(k)$. Finally, the estimated model $Y$ can be compared with the real values of doses. So basically, Eq. 7 is a projection of the mapped matrix's eigenvectors on the feature space. As a result, one may deflate the matrix $\Psi$, which means excluding some eigenvectors. Consequently, the deflating process handles the harmful effects associated with multicollinearity presented in the original Euclidean space. $\|\cdot\|$ is the norm of vector; $Y$ is the predicted value from the input $M ; \eta$ is a vector of regression coefficients and $\epsilon^{\prime}$ is a vector of random errors in the feature space.

\subsection{Validation of KPCR method for dose-response}

The KPCR method provides results for dose-response in association with the number of principal components $(k)$, so it is possible to validate this method by comparing it with measurements taken with the UV-Vis spectrophotometry equipment for all doses and concentrations of this work. These validation and statistical error methods will be used with criteria established to define the method accuracy; they are Root Mean Square Percentage Error (RMSPE) defined by Eq. 8, and Mean Absolute Percentage Error (MAPE) defined by Eq. 9 , as follows:
RMSPE $=\sqrt{\frac{1}{n} \sum_{i=1}^{n}\left(\frac{y_{i}-\hat{y}_{i}}{y_{i}}\right)^{2}} \times 100 \%$

MAPE $=\sqrt{\frac{1}{n} \sum_{i=1}^{n}\left|\frac{y_{i}-\hat{y}_{i}}{y_{i}}\right|} \times 100 \%$,

where $y_{i}$ are the real values, $\hat{y}_{i}$ are the predicted values, and $n$ is the amount of data used in the prediction. Thus, RMSPE and MAPE methods have critical criteria characteristics of predicting values [49].

\section{Results and discussion}

The illuminance measurements versus exposure time, for the blue LED light source are shown in Fig. 1a. The illuminance values increase over time, until their values stabilize: for this curve, a 3rd-degree polynomial fit $\left(R^{2}=0.9611\right)$ was obtained. Consequently, the CHS detector samples were irradiated after the stabilization period of the radiation source; according to the curve, this time will be obtained in $>19.7 \mathrm{~min}$ (in this work an adequate time for initial measurements is around $60 \mathrm{~min}$ ).

The spectra of the CHS detector samples are shown in Fig. $1 \mathrm{~b}$ for concentrations of $1,2,3,4,5$, and $6 \mathrm{mg} / \mathrm{ml}$, in a wavelength range from 400 to $700 \mathrm{~nm}$. There is a region with higher absorbance values from 400 to $450 \mathrm{~nm}$ and decay of these values up to $700 \mathrm{~nm}$. The absorbance values also vary with the associated concentrations, in ascending order. Thus, the UV-Vis spectroscopy technique made it possible to obtain the spectra of the CHS detector samples.

In Fig. 2a, the calibration curve shows the squared Pearson correlation coefficient $\left(R^{2}\right)$ of 0.9895 ; the absorbances obtained adequately responded to the various concentrations. In Fig. 2b, linearity was plotted versus wavelength, to obtain the wavelength for the calibration curve, providing the largest $R^{2}$; this value was $400 \mathrm{~nm}$, using all concentrations. Sensitivity versus wavelength behavior for the CHS detector samples for all concentrations are shown in Fig. 2c. The results indicate the wavelength with the highest sensitivity, which is $400 \mathrm{~nm}$; afterwards, the sensitivity decreases with the increase in wavelength, and it shows that at $400 \mathrm{~nm}$ the maximum values for both linearity and sensitivity occur. For concentrations greater than $6 \mathrm{mg} / \mathrm{ml}$, significant signal-tonoise ratios (SNRs) appear in the spectrum, discarded in this work. It is worth mentioning that the results of Fig. 2a-d are from non-irradiated CHS detector samples.

The absorbance versus wavelength for the CHS detector samples, UV-Vis spectra, for doses of $0.60,1.20,1.80$, $2.40,3.00,3.60,4.20,4.80,5.40$, and $6.00 \mathrm{~kJ} / \mathrm{cm}^{2}$, and for all concentrations used in this work are shown in Fig. 3. 


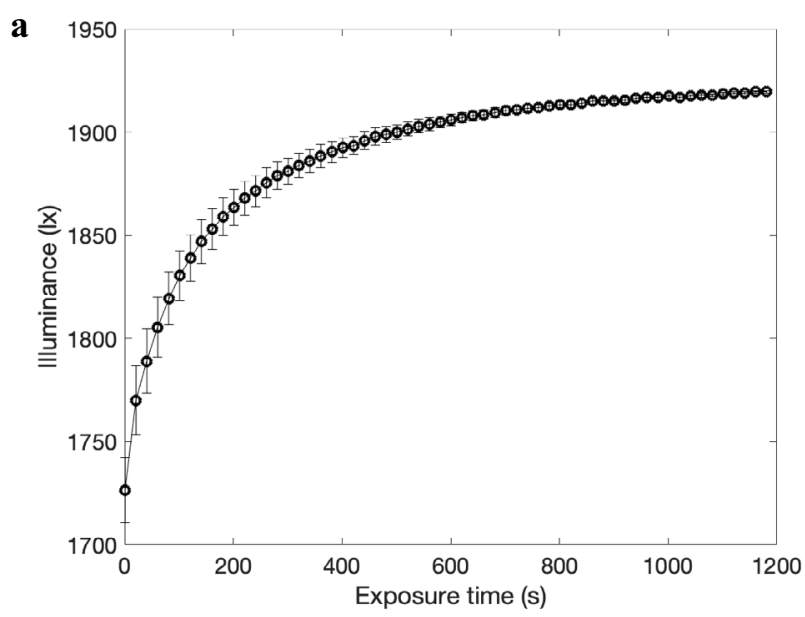

b

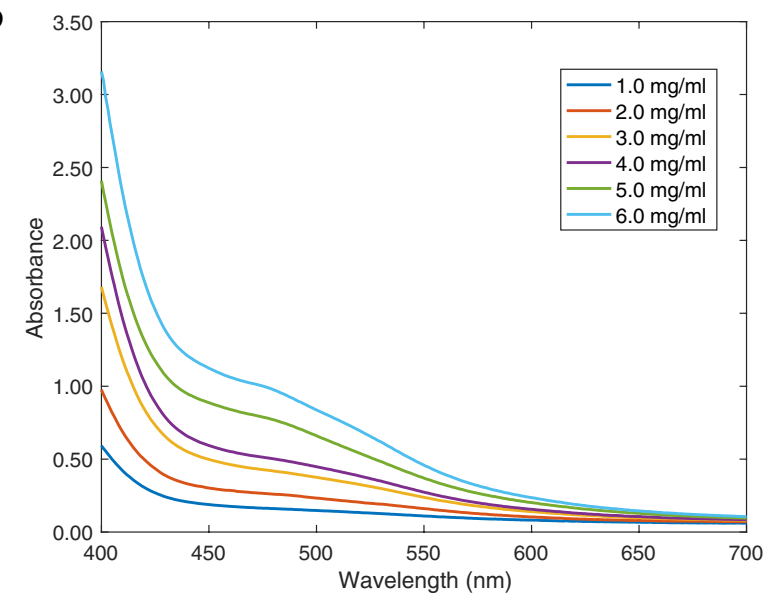

Fig. 1 a Illuminance versus exposure time for blue LED source irradiation, in the time 0 up to $1180 \mathrm{~s}$. Error bars are the standard deviations for triplicate measurements, $\mathbf{b}$ absorbance versus wavelength, UV-Vis spectra, for CHS detector samples with 1, 2, 3, 4, 5, and $6 \mathrm{mg} / \mathrm{ml}$ concentration, respectively. In this case, the non-concentration cuvette contained air. The uncertainty of the measurements obtained was lower than $1 \%$. The uncertainty was of type $\mathrm{C}$, which considers the uncertainties A (from measurements) and the uncertainties B (from equipment)

First, for all concentrations, it is possible to observe variations in their absorbance, thus proving the interaction of radiation from the blue LED source and the detector. The maximum absorbances (peaks) for the concentrations of $1,2,3,4,5$, and $6 \mathrm{mg} / \mathrm{ml}$ are in the wavelength regions of $(478.0 \pm 1.2 \mathrm{~nm}),(477.0 \pm 1.7 \mathrm{~nm}),(508.0 \pm 1.5 \mathrm{~nm})$, $(478.0 \pm 1.0 \mathrm{~nm}),(476.0 \pm 0.7 \mathrm{~nm})$, and $(477.0 \pm 0.3 \mathrm{~nm})$, respectively.

These results demonstrate that most of the longest wavelengths are in the blue radiation source. These results follow the literature where the radiation wavelength is considered close to the detector wavelength [50,51]. During the irradiations, it was also possible to observe that the CHS detector samples did not change color significantly, so they cannot be classified as Yes/No irradiated detectors for the dosing interval analyzed in this work.

For some linearity values, with their corresponding wavelengths, they are shown in Table 1 . These values are also associated with the concentrations of the CHS detector samples; this result shows that there are more regions in which the detector can be applied with adequate linearity results. It is possible to observe that for each concentration there is a value for linearity; each linear fit was carried out at the wavelength that provides the highest value of linearity (wavelength method). The maximum $R^{2}$ values were obtained, for 541, 530, 423, 443, 533, and $422 \mathrm{~nm}$, and $1,2,3,4,5$, and $6 \mathrm{mg} / \mathrm{ml}$, respectively.

In Table 2 are shown the polynomial fit and linear fit for sensitivity and linearity; these results give adequate approximation mathematics for the curves from the measurements. The values for $R^{2}$ are $\geq 0.9507$ and $\geq 0.9911$, for the polynomial fit and linear fit, respectively. Figure 3 shows the maximum values of absorbance and Table 1 the maximum values of $R^{2}$. A region with higher absorbance values will not necessarily present the maximum $R^{2}$ values.

In Table 3, standard deviations are shown for all concentrations and associated with a region of 400 up to $420 \mathrm{~nm}$, with irradiated and non-irradiated CHS detector samples. These results are important for the experimental response reproducibility of the detector; they can also infer that the standard deviation value decreases with the increase of the wavelength.

The results on sensitivity versus wavelength, for the CHS detector samples, are shown in Fig. 4. The results for sensitivities indicate regions and peaks where the CHS detector sample is more sensitive to non-ionizing radiation. For the concentrations of 1,2 , and $4 \mathrm{mg} / \mathrm{ml}$ the peak is at $484 \mathrm{~nm}$, for $3 \mathrm{mg} / \mathrm{ml}$ the peak is at $495 \mathrm{~nm}$ and for concentrations 5 and $6 \mathrm{mg} / \mathrm{ml}$ the peak is at $478 \mathrm{~nm}$. In Table 2 on the left, squared Pearson correlation coefficients $\left(R^{2}\right)$ are shown for each concentration, which is greater than 0.9507 , and these results infer that the sensitivity for the CHS detector samples can be determined through mathematical equations for the sensitivity curves.

Figure 5 presents the correlation matrix from CHS detector samples irradiated with ten doses and six concentrations. The results indicated that this matrix had highlighted a significant multicollinearity degree among the data $(p<0.01)$. Therefore, a multidimensional analysis was performed through the k-means algorithm seeking to evaluate the concentration effects over absorbance readings for the absorbed doses ranging from 0.60 to $6 \mathrm{~kJ} / \mathrm{cm}^{2}$. Therefore, as stated in Sect. 2.4, the whole dataset underwent the PCA transformation to assess the absorbed dose influence. This process was performed for the absorbance of the samples from to $700 \mathrm{~nm}$, for each concentration ranging from 1 to $6 \mathrm{mg} / \mathrm{ml}$. 
a

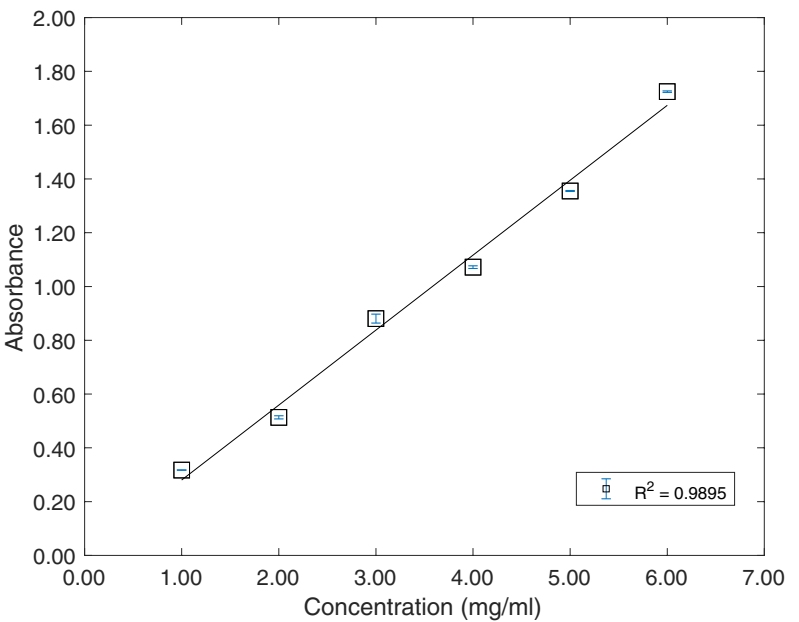

b

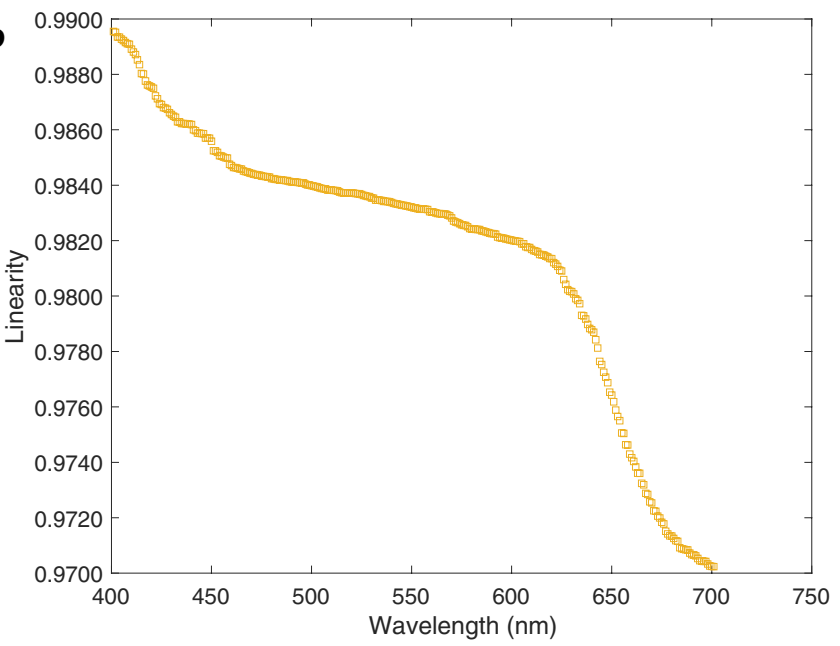

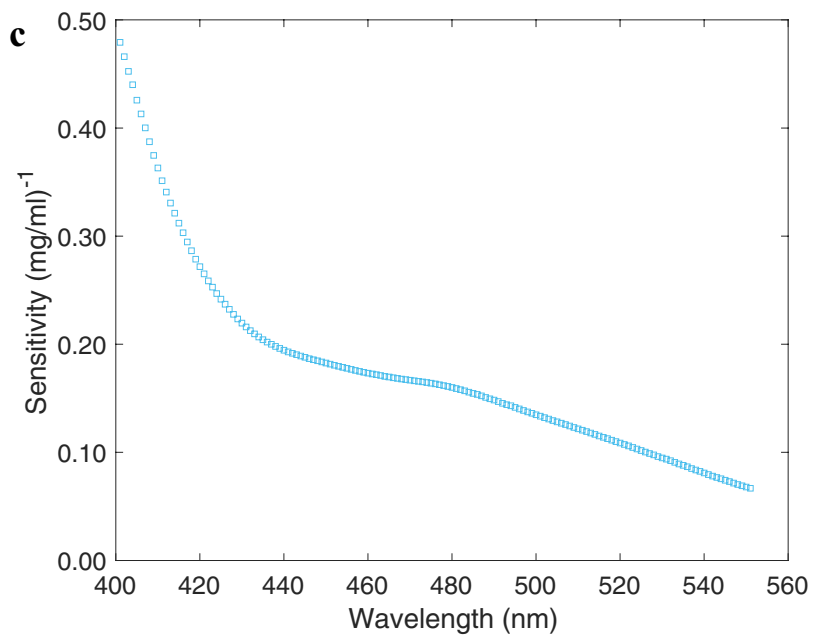

Fig. 2 a Calibration curves of six concentrations of CHS detector samples: $1,2,3,4,5$, and $6 \mathrm{mg} / \mathrm{ml}$, with $R^{2}=0.9895$, the standard deviations were $<1 \%$ for the triplicate measurements, b linearity versus wavelength for all concentrations used in this work, and c Sen- sitivity versus wavelength for concentrations from 1 up to $6 \mathrm{mg} / \mathrm{ml}$. The CHS detector samples were not irradiated in these results and have a cuvette containing air as standard sample
The results on Principal Component Analysis (PCA) and k-means for all concentrations, for CHS detector samples, are shown in Fig. 6. The k-means identified cluster regions that were projected over the two-dimensional PCA component space for visualization purposes. Thus, two cluster regions were found; as a result, more than $99.97 \%$ of the variance was explained using the first principal component, which agrees with the overall squared Pearson correlation coefficient $\left(R^{2}\right)$ that was above 0.9970 for the doses. These results also show the predominance of the first principal component concerning the second one while explaining the variance regarding the absorbance readings as a concentration function. Thus, within the two identified clusters, the first contained $85.50 \%$ of samples, while the second with the remaining. Although, when weighting the dimensional effect, the cumulative variance accounted 1:45 fold ratio between the first and second eigenvalues. Thus, the second principal dimensional described only $2.22 \%$ of the first principal component, undermining the decrease in linearity as previously observed. As a result, it can be generalized that the linearity variation was inexpressive concerning the concentration variation, i.e., the overall linearity is independent of the concentration. Hence, in evaluating the concentrationeffect over the linearity, it was possible to ascertain, through the cluster tail, that the second cluster manifested a decrease in the linearity as the wavenumber increased for the concentrations of 3 and $6 \mathrm{mg} / \mathrm{ml}$. 
Fig. 3 Absorbance versus wavelength, for CHS detector samples for ten doses: 0.60 , $1.20,1.80,2.40,3.00,3.60$, $4.20,4.80,5.40$, and $6.00 \mathrm{~kJ} /$ $\mathrm{cm}^{2}$ (blue LED source). All measurements were taken with $1,2,3,4,5$, and $6 \mathrm{mg} / \mathrm{ml}$ concentrations. In this case, the non-irradiated cuvette contained CHS detector solution of 1,2 , $3,4,5$, and $6 \mathrm{mg} / \mathrm{ml}$ concentrations. The uncertainty of the measurements obtained was lower than $1 \%$. The uncertainty was of type $\mathrm{C}$, which considers the uncertainties A (from measurements) and the uncertainties $\mathrm{B}$ (from equipment)
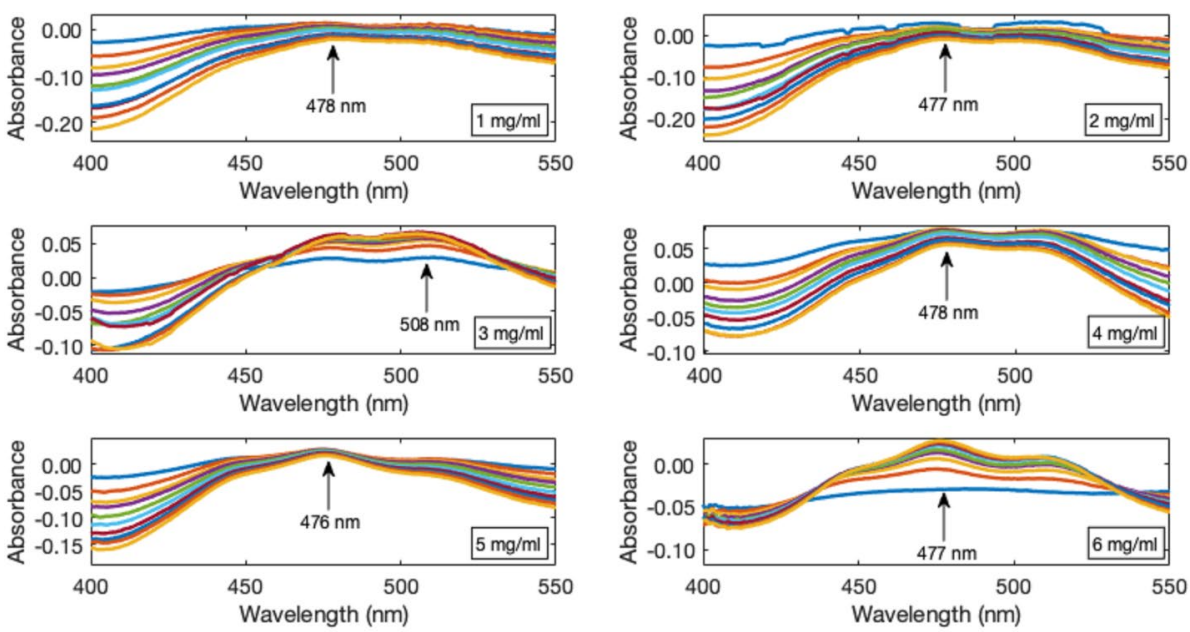

Table 1 The maximum values for squared Pearson correlation coefficient $\left(R^{2}\right)$ and their appropriate locations in the spectrum (wavelength), for CHS detector sample concentrations of $1,2,3,4,5$, and
$6 \mathrm{mg} / \mathrm{ml}$, and for doses: $0.60,1.20,1.80,2.40,3.00,3.60,4.20,4.80$, 5.40 , and $6.00 \mathrm{~kJ} / \mathrm{cm}^{2}$ (blue LED source)

\begin{tabular}{|c|c|c|c|c|c|c|c|c|c|c|c|}
\hline \multicolumn{2}{|c|}{$1 \mathrm{mg} / \mathrm{ml}$} & \multicolumn{2}{|c|}{$2 \mathrm{mg} / \mathrm{ml}$} & \multicolumn{2}{|c|}{$3 \mathrm{mg} / \mathrm{ml}$} & \multicolumn{2}{|c|}{$4 \mathrm{mg} / \mathrm{ml}$} & \multicolumn{2}{|c|}{$5 \mathrm{mg} / \mathrm{ml}$} & \multicolumn{2}{|c|}{$6 \mathrm{mg} / \mathrm{ml}$} \\
\hline$R^{2}$ & $\begin{array}{l}\text { Wave- } \\
\text { length } \\
(\mathrm{nm})\end{array}$ & $R^{2}$ & $\begin{array}{l}\text { Wave- } \\
\text { length } \\
(\mathrm{nm})\end{array}$ & $R^{2}$ & $\begin{array}{l}\text { Wave- } \\
\text { length } \\
(\mathrm{nm})\end{array}$ & $R^{2}$ & $\begin{array}{l}\text { Wave- } \\
\text { length } \\
(\mathrm{nm})\end{array}$ & $R^{2}$ & $\begin{array}{l}\text { Wave- } \\
\text { length } \\
(\mathrm{nm})\end{array}$ & $R^{2}$ & $\begin{array}{l}\text { Wave- } \\
\text { length } \\
(\mathrm{nm})\end{array}$ \\
\hline 0.9944 & 541 & 0.9962 & 530 & 0.9916 & 423 & 0.9920 & 443 & 0.9968 & 533 & 0.9891 & 422 \\
\hline 0.9941 & 545 & 0.9960 & 447 & 0.9915 & 421 & 0.9918 & 444 & 0.9968 & 535 & 0.9886 & 549 \\
\hline 0.9939 & 542 & 0.9950 & 531 & 0.9913 & 426 & 0.9917 & 447 & 0.9968 & 541 & 0.9856 & 551 \\
\hline 0.9937 & 446 & 0.9935 & 461 & 0.9909 & 427 & 0.9916 & 446 & 0.9967 & 537 & 0.9851 & 420 \\
\hline 0.9936 & 445 & 0.9930 & 460 & 0.9909 & 425 & 0.9916 & 442 & 0.9967 & 540 & 0.9843 & 424 \\
\hline 0.9934 & 443 & 0.9929 & 463 & 0.9909 & 422 & 0.9915 & 448 & 0.9965 & 532 & 0.9830 & 419 \\
\hline 0.9931 & 436 & 0.9927 & 462 & 0.9901 & 420 & 0.9914 & 441 & 0.9964 & 441 & 0.9827 & 423 \\
\hline 0.9930 & 444 & 0.9898 & 493 & 0.9844 & 428 & 0.9911 & 449 & 0.9963 & 442 & 0.9818 & 421 \\
\hline 0.9927 & 440 & 0.9896 & 490 & 0.9830 & 419 & 0.9906 & 440 & 0.9963 & 542 & 0.9808 & 418 \\
\hline 0.9927 & 439 & 0.9891 & 492 & 0.9829 & 429 & 0.9906 & 439 & 0.9962 & 536 & 0.9795 & 548 \\
\hline 0.9925 & 543 & 0.9886 & 543 & 0.9819 & 430 & 0.9903 & 438 & 0.9961 & 547 & 0.9782 & 417 \\
\hline 0.9924 & 547 & 0.9879 & 494 & 0.9809 & 418 & 0.9900 & 450 & 0.9961 & 544 & 0.9762 & 416 \\
\hline 0.9924 & 536 & 0.9872 & 529 & 0.9795 & 431 & 0.9893 & 451 & 0.9960 & 440 & 0.9751 & 425 \\
\hline 0.9922 & 550 & 0.9871 & 449 & 0.9784 & 417 & 0.9892 & 437 & 0.9960 & 539 & 0.9744 & 547 \\
\hline 0.9921 & 441 & 0.9870 & 491 & 0.9775 & 432 & 0.9885 & 436 & 0.9959 & 531 & 0.9695 & 412 \\
\hline 0.9920 & 449 & 0.9866 & 443 & 0.9755 & 416 & 0.9881 & 452 & 0.9959 & 534 & 0.9694 & 426 \\
\hline 0.9919 & 448 & 0.9865 & 442 & 0.9750 & 433 & 0.9874 & 435 & 0.9959 & 530 & 0.9690 & 415 \\
\hline 0.9920 & 549 & 0.9865 & 544 & 0.9737 & 415 & 0.9873 & 453 & 0.9958 & 550 & 0.9685 & 408 \\
\hline 0.9916 & 442 & 0.9862 & 446 & 0.9720 & 434 & 0.9871 & 538 & 0.9958 & 543 & 0.9659 & 546 \\
\hline
\end{tabular}

Figure 7 presents the Cumulative Distribution Function (CDF) versus squared Pearson correlation coefficient $\left(R^{2}\right)$ for all concentrations. The order in the legend is ascending, but the results do not follow the order shown in the legend. These results show that the organization of the different spectra from the concentrations provide distinct and 
Table 2 Linear fit equations with six concentrations and ten doses. The respective squared Pearson correlation coefficients $\left(R^{2}\right)$ correspond to the absorbance values with wavelengths at $541,530,423,443,533$, and $422 \mathrm{~nm}$ for $1,2,3,4,5$, and $6 \mathrm{mg} / \mathrm{ml}$, respectively.

\begin{tabular}{lllllll}
\hline $\begin{array}{l}\text { Concentra- } \\
\text { tion }(\mathrm{mg} / \mathrm{ml})\end{array}$ & Equation (Fig. 6) & Fit & $R^{2}$ & Equation (Table 1) & Fit & $R^{2}$ \\
\hline 1 & $y=4.5 \times 10^{-9} x^{3}-9.4 \times 10^{-6} x^{2}+0.006 x-1.218$ & Polynomial & 0.9860 & $y=-1.1 \times 10^{-2} x-0.001$ & Linear & 0.9945 \\
2 & $y=6.0 \times 10^{-9} x^{3}-1.2 \times 10^{-5} x^{2}+0.008 x-1.516$ & Polynomial & 0.9793 & $y=-1.4 \times 10^{-2} x+0.013$ & Linear & 0.9967 \\
3 & $y=-2.0 \times 10^{-8} x^{3}+2.5 \times 10^{-5} x^{2}-0.010 x-1.384$ & Polynomial & 0.9770 & $y=-1.5 \times 10^{-2} x-0.001$ & Linear & 0.9918 \\
4 & $y=-2.5 \times 10^{-8} x^{3}+3.4 \times 10^{-5} x^{2}-0.014 x+2.064$ & Polynomial & 0.9627 & $y=-1.2 \times 10^{-2} x+0.013$ & Linear & 0.9923 \\
5 & $y=6.9 \times 10^{-9} x^{3}-1.3 \times 10^{-6} x^{2}+0.008 x-1.522$ & Polynomial & 0.9678 & $y=-1.1 \times 10^{-2} x+0.003$ & Linear & 0.9969 \\
6 & $y=-1.6 \times 10^{-8} x^{3}+2.1 \times 10^{-5} x^{2}-0.009 x+1.193$ & Polynomial & 0.9507 & $y=-4.1 \times 10^{-3} x-0.030$ & Linear & 0.9911 \\
\hline
\end{tabular}

A polynomial fit was obtained for the CHS detector samples to all concentrations, spectra, and doses. The values of $y$ and $x$ are the absorbance and dose, respectively

independent $R^{2}$ and CDF values, as can be seen in Fig. 7 . These results corroborate those obtained by the previous analysis for the PCA and k-means methods. This means that most of the data from the CHS detector samples are in the region of strong linearity, specifically with values of $80 \%$ for the CDF provides $R^{2} \geq 0.9706$, for all concentrations and dose data of the CHS detector samples.

Figure 8 shows the values predicted from the KPCR method $(k=2)$ in comparison with the measured values of the CHS detector samples with all concentrations. As a corollary of the above observation, the results show KPCR regression lines employed to quantify the statistical significance of the linearity variation to the concentration effects. The hypothesis test through the ANOVA, in terms of the difference of mean values, showed that the $R^{2}$ for all concentrations is not different $(p<0.01)$. The result for ANOVA indicates that the null hypothesis is rejected, thus the mean values for all six groups are different and statistically significant; therefore, the ANOVA method may be applied here. Thus, the overall linearity of the adjusted multivariate KPCR model indicates invariance of linearity taking simultaneously the effects of the concentration and the spectral (wavenumbers) variations. Table 4 shows the values for the squared Pearson correlation coefficient $\left(R^{2}\right)$ associated with the concentrations and the number of principal components $(k)$ from the KPCR method. These results indicate the evolution of the number of principal components from $k=1$ up to $k=9$. With the increase in these values, $R^{2}$ will also increase until their maximum value is obtained, for example, for the concentration of $6 \mathrm{mg} / \mathrm{ml}$, the maximum values were already reached in $k=7$. This fact demonstrates that the KPCR method fitted the entire concentrations made in the measurements and not just a concentration in its analysis, that is, for global analysis of the system an appropriate method is the KPCR, which provided adequate results for comparisons with the measurements of the CHS detector samples.

Statistical error methods as the Root Mean Square Percentage Error (RMSPE) and the Mean Absolute Percentage Error (MAPE) versus number of principal component $(k)$ for $1,2,3,4,5$, and $6 \mathrm{mg} / \mathrm{ml}$ concentrations are presented in Fig. 9a-f, respectively. For the initial analysis, the best criterion for comparisons between the RMSPE and MAPE methods was chosen in which the error $<10 \%$ is considered highly accurate. In this criterion, the concentration of $1 \mathrm{mg} /$ $\mathrm{ml}$ requires $k=1$ for both MAPE and RMSPE methods, the concentration of $2 \mathrm{mg} / \mathrm{ml}$ requires $k=1$ (MAPE) and $k=2$ (RMSPE), the other concentrations of 3, 4, 5, and $6 \mathrm{mg} /$ $\mathrm{ml}$, for MAPE and RMSPE require $k=2$. This work will assign a criterion with more accuracy than observed in the literature, that is, an analysis for an error $<5 \%$ was considered here as excellent accuracy. For this second analysis, 


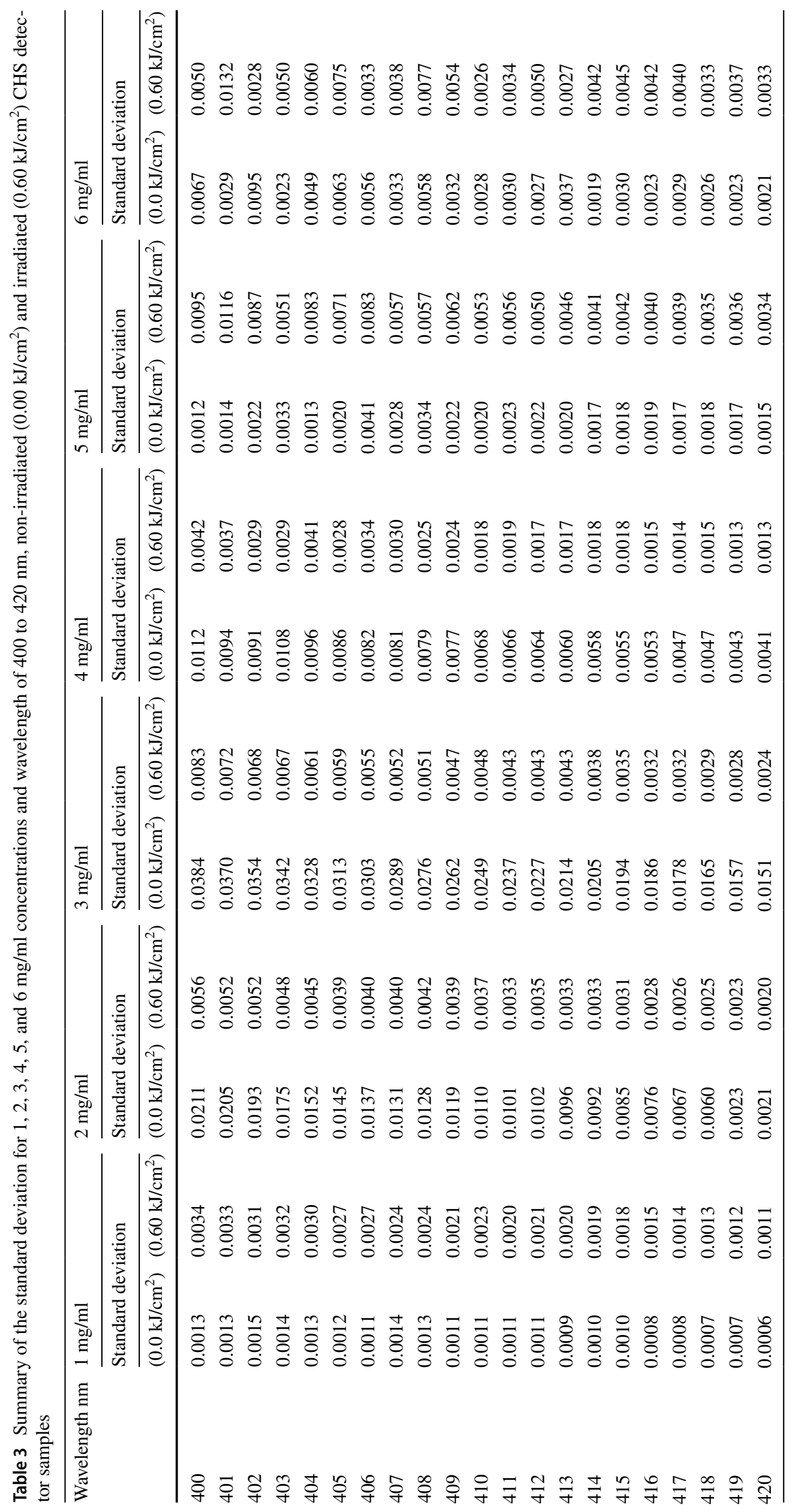


Fig. 4 Sensitivity versus wavelength, for CHS detector samples and ten doses: 0.60 , $1.20,1.80,2.40,3.00,3.60$, $4.20,4.80,5.40$, and $6.00 \mathrm{~kJ} /$ $\mathrm{cm}^{2}$ (blue LED source), and six concentrations: $1,2,3,4,5$, and $6 \mathrm{mg} / \mathrm{ml}$

Fig. 5 Correlation matrix for CHS detector samples with $0.60,1.20,1.80,2.40,3.00$, $3.60,4.20,4.80,5.40$, and $6.00 \mathrm{~kJ} / \mathrm{cm}^{2}$ doses, and 1, 2, 3, 4,5 , and $6 \mathrm{mg} / \mathrm{ml}$ concentrations
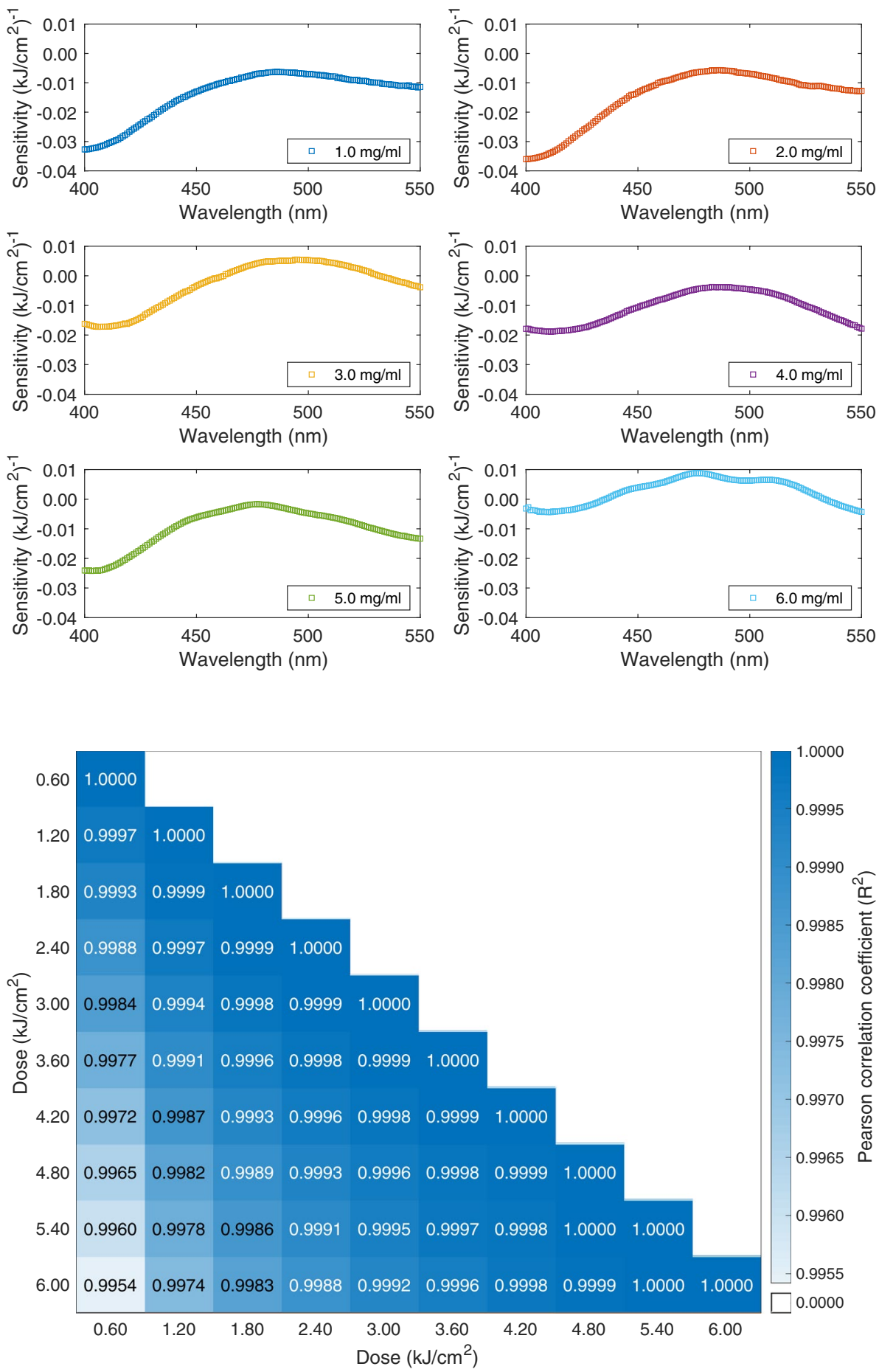

the concentration of $1 \mathrm{mg} / \mathrm{ml}$ requires $k=2$ for both MAPE and RMSPE methods, the concentration of $2 \mathrm{mg} / \mathrm{ml}$ requires $k=3$ for both MAPE and RMSPE methods, the concentration of $3 \mathrm{mg} / \mathrm{ml}$ requires $k=2$ (MAPE) and $k=3$ (RMSPE), the concentration of $4 \mathrm{mg} / \mathrm{ml}$ requires $k=3$ (MAPE) and $k=4$ (RMSPE), the concentrations of 5 and $6 \mathrm{mg} / \mathrm{ml}$ require $k=4$ and $k=5$ for both, MAPE and RMSPE methods, respectively. For all analyzed concentrations: (i) the RMSPE values are greater than the MAPE values, (ii) the errors are greater when $k=1$, (iii) they converge, when the predictive data are equal to the real ones, for $k=9$. 

Analysis (PCA) for 1, 2, 3, 4, 5 , and $6 \mathrm{mg} / \mathrm{ml}$ concentrations. The first principal component is represented by the $x$ axis, while the second main component is represented by the $y$ axis. The k-means clusters can also be observed, on the left side the first cluster and its centroid, and to the right the second cluster and its centroid
Fig. 6 Principal Component

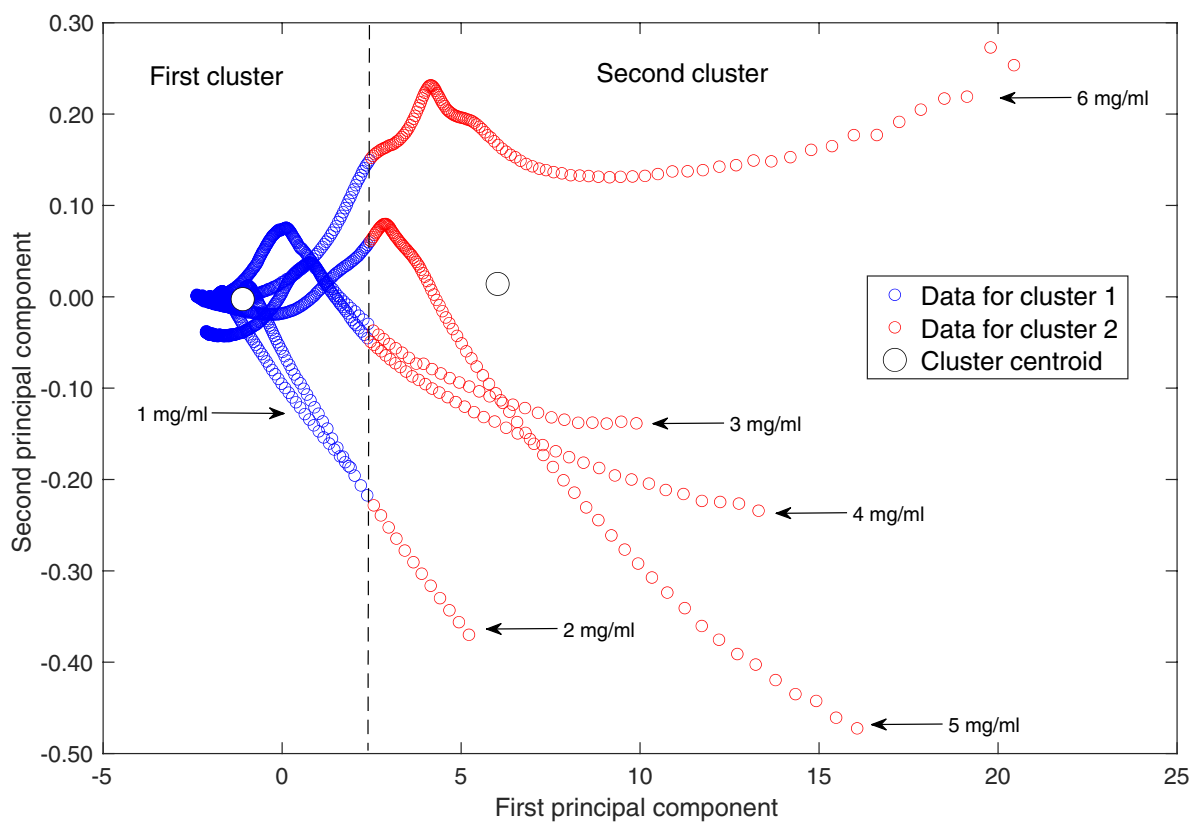

Fig. 7 Cumulative distribution function $(\mathrm{CDF})$ versus squared Pearson correlation coefficient $\left(R^{2}\right)$, for $1,2,3,4,5$, and $6 \mathrm{mg} /$ $\mathrm{ml}$ concentrations

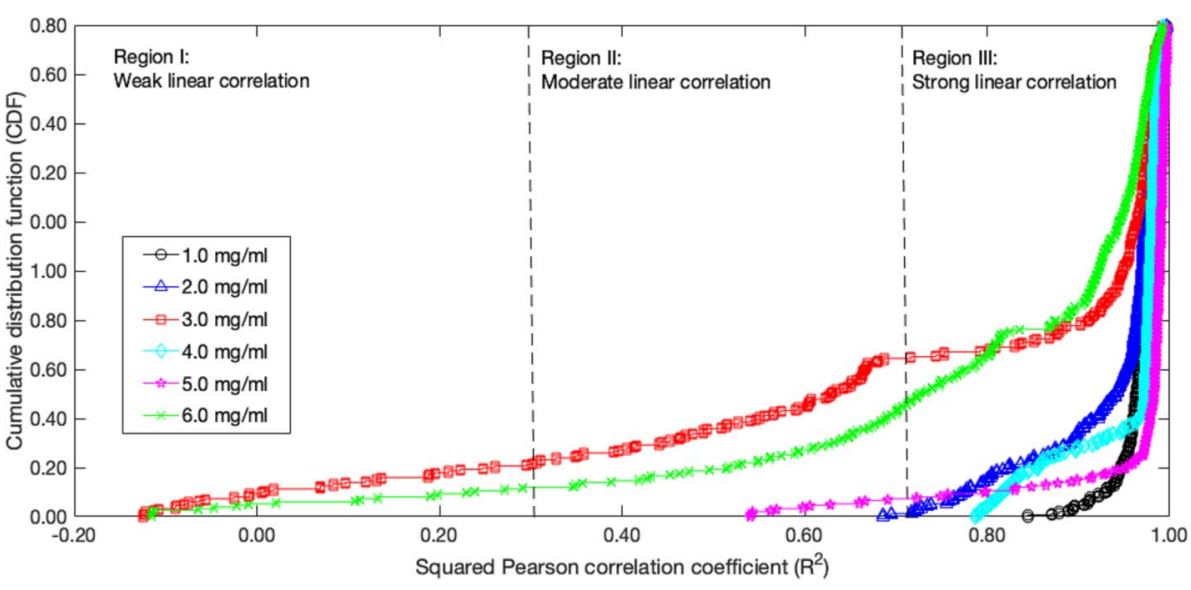

\section{Conclusions}

The CHS detector presents preliminary results which can be useful in measurements for photodynamic therapy, such as: (i) the preparation of the CHS samples is simple, following the steps they can be easily reproduced; (ii) the application of the UV-Vis spectrophotometric technique to the CHS detector samples could be performed with low standard deviations, thus guaranteeing the reproducibility of the results obtained for both irradiated and non-irradiated samples; (iii) the irradiation system was effective in irradiating the samples and the blue LED light sensitized the photosensitizer in the region of the detector wavelength; (iv) the results for linearity through the best wavelength were adequate, thus providing a quick analysis of the detector at a specific wavelength and visually determined on the graph (peaks) of absorbance versus wavelength; (v) the correlation matrix, PCA together with k-means provided information regarding the clusters and the main components; these were determined and were accurate for the 
Fig. 8 Predicted dose versus measured dose, through the KPCR method, using $k=2$ as number principal of component, for CHS detector samples with $1,2,3,4,5$, and $6 \mathrm{mg} / \mathrm{ml}$ concentrations
Table 4 Squared Pearson correlation coefficient $\left(R^{2}\right)$ versus number of principal component $(k)$ for $1,2,3,4,5$, and $6 \mathrm{mg} / \mathrm{ml}$ concentrations for CHS detector samples irradiated with blue LED source

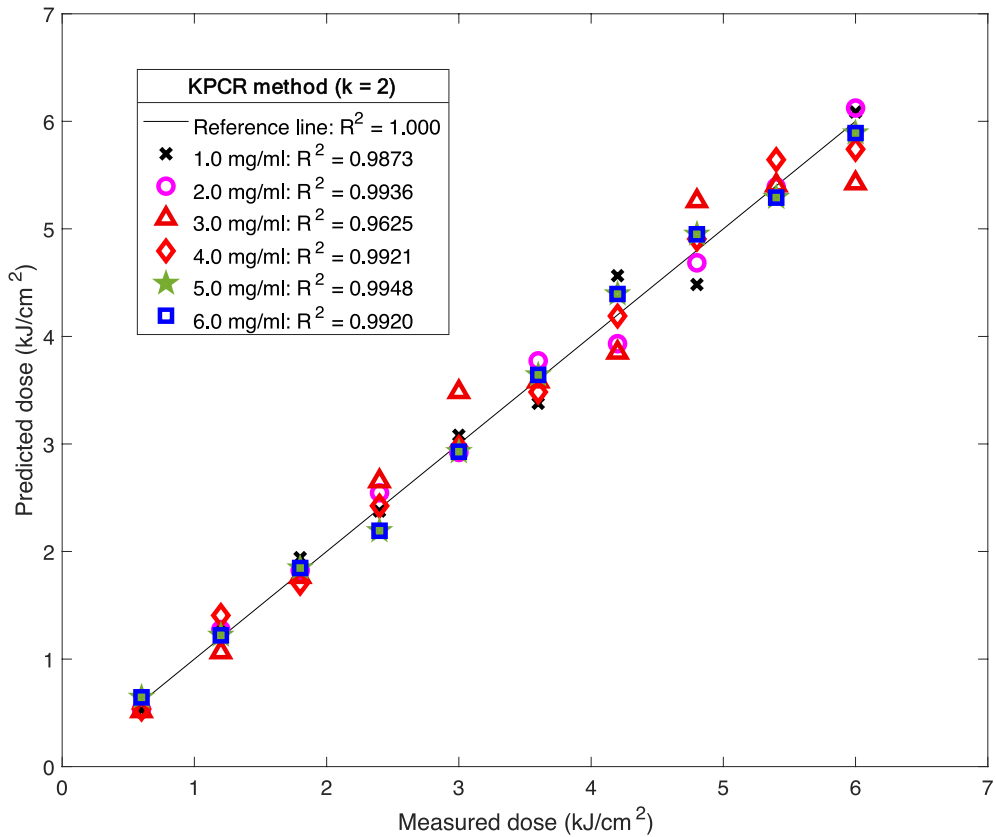

most robust employed analyses; (vi) the sensitivity of the CHS detector was also determined with irradiated and non-irradiated samples, the results showing that in both situations the greatest sensitivity is observed in the region of greatest linearity; (vii) the KPCR method had excellent results when applied to the CHS detector spectra; with the control of the number of main components, it was possible to determine how close the $R^{2}$ values were to the experimental values; (viii) the results for linearity (both for the method of choosing the wavelength where $R^{2}$ occurs, and for KPCR method) can be obtained through mathematical methods and functions; (ix) the RSMPE and MAPE methods for statistical errors were used, and their results showed that the KPCR method is confident and determinant for the maximum agreement between the predictive and measured values, through the number of main components $(k)$. Therefore, it is concluded that the feasibility of employing the CHS detector samples was confirmed in measurements involving photodynamic therapy measurements. 
Fig. 9 Root Mean Square Percentage Error (RMSPE) and Mean Absolute Percentage Error (MAPE) versus number of principal components from $k=1$ up to $k=9$, for a $1 \mathrm{mg} / \mathrm{ml}$, b $2 \mathrm{mg} / \mathrm{ml}$, c $3 \mathrm{mg} / \mathrm{ml}$, d $4 \mathrm{mg}$ / $\mathrm{ml}$, e $5 \mathrm{mg} / \mathrm{ml}$, and f $6 \mathrm{mg} / \mathrm{ml}$ concentrations. The standard deviations of the RMSPE and MAPE methods obtained were lower than $1 \%$
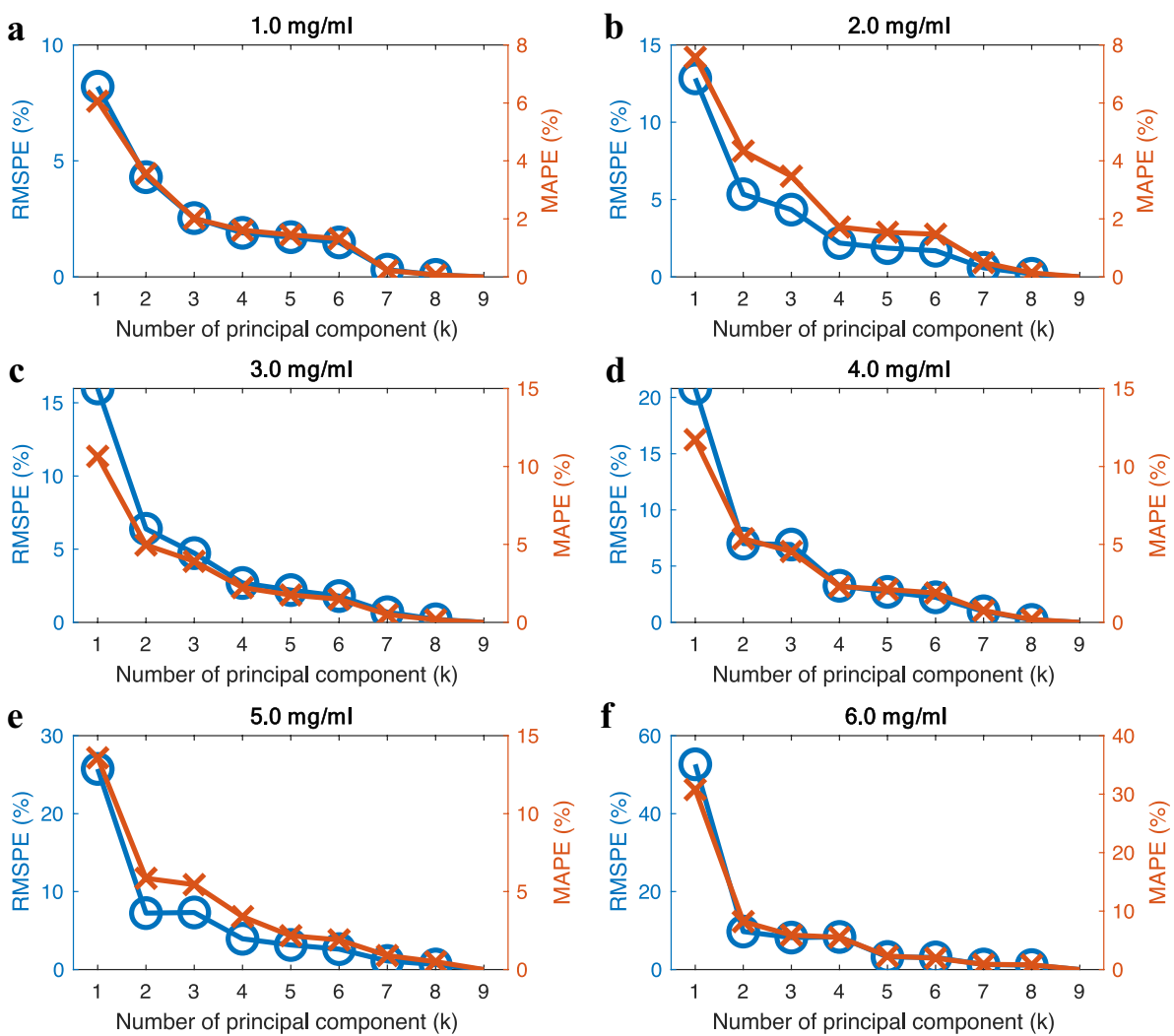

Acknowledgements The authors thank the Brazilian funding agencies CNPq (Projects 104486/2019-8, 164981/2020-9 and 301335/2016-8) and FAPESP (Project 2018/05982-0) for partial financial support.

\section{Declarations}

Conflict of interest There are no conflicts to declare.

\section{References}

1. Xiao, M., Fan, J., Li, M., Xu, F., Zhao, X., Xi, D., et al. (2020). A photosensitizer-inhibitor conjugate for photodynamic therapy with simultaneous inhibition of treatment escape pathways. Biomaterials, 257, 120262. https://doi.org/10.1016/j.biomaterials.2020. 120262

2. Miletto, I., Gionco, C., Paganini, M. C., Martinotti, S., Ranzato, E., Giamello, E., et al. (2020). Vis-NIR luminescent lanthanidedoped core-shell nanoparticles for imaging and photodynamic therapy. Journal of Photochemistry and Photobiology A: Chemistry. https://doi.org/10.1016/j.jphotochem.2020.112840

3. Bartusik-Aebisher, D., Ożóg, Ł, \& Aebisher, D. (2021). Alternative methods of photodynamic therapy and oxygen consumption measurements-a review. Biomedicine \& Pharmacotherapy, 134, 111095. https://doi.org/10.1016/j.biopha.2020.111095

4. de Oliveira, L. N., do Nascimento, E. O., \& Caldas, L. V. E. (2021). New Fricke Xylenol Liquid detector doped with methylene blue (FXL-mblue) irradiated with red LED light. Journal of Luminescence, 230, 117730. https://doi.org/10.1016/j.jlumin. 2020.117730

5. Lahoz, F., Scholz, L. E., Boto, A., \& Díaz, M. (2020). FRET mechanism between a fluorescent breast-cancer drug and photodynamic therapy sensitizers. Spectrochimica Acta-Part A: Molecular and Biomolecular Spectroscopy, 239, 118498. https:// doi.org/10.1016/j.saa.2020.118498

6. Liu, R., Gao, Y., Liu, N., \& Suo, Y. (2020). Nanoparticles loading porphyrin sensitizers in improvement of photodynamic therapy for ovarian cancer. Photodiagnosis and Photodynamic Therapy. https://doi.org/10.1016/j.pdpdt.2020.102156

7. Warrier, A., Mazumder, N., Prabhu, S., Satyamoorthy, K., \& Murali, T. S. (2020). Photodynamic therapy to control microbial biofilms. Photodiagnosis and Photodynamic Therapy. https://doi. org/10.1016/j.pdpdt.2020.102090

8. Chen, J., Fan, T., Xie, Z., Zeng, Q., Xue, P., Zheng, T., et al. (2020). Advances in nanomaterials for photodynamic therapy applications: status and challenges. Biomaterials, 237, 119827. https://doi.org/10.1016/j.biomaterials.2020.119827

9. Dong, J., Zhang, Y., Guo, P., Xu, H., Wang, Y., \& Yang, D. (2020). GQDs/hMSN nanoplatform: singlet oxygen generation for photodynamic therapy. Journal of Drug Delivery Science and Technology. https://doi.org/10.1016/j.jddst.2020.102127

10. Günsel, A., Güzel, E., Bilgiçli, A. T., Atmaca, G. Y., Erdoğmuş, A., \& Yarasir, M. N. (2017). Synthesis and investigation of photophysicochemical properties of novel ketone-substituted gallium (III) and indium (III) phthalocyanines with high singlet oxygen yield for photodynamic therapy. Journal of Luminescence, 192, 888-892. https://doi.org/10.1016/j.jlumin.2017.08.014

11. Muchowicz, A., Wachowska, M., Stachura, J., Tonecka, K., Gabrysiak, M., Wołosz, D., et al. (2017). Inhibition of lymphangiogenesis impairs antitumour effects of photodynamic therapy and checkpoint inhibitors in mice. European Journal of Cancer, 83, 19-27. https://doi.org/10.1016/j.ejca.2017.06.004

12. Kaleta-Richter, M., Kawczyk-Krupka, A., Aebisher, D., BartusikAebisher, D., Czuba, Z., \& Cieślar, G. (2019). The capability and potential of new forms of personalized colon cancer treatment: 
immunotherapy and photodynamic therapy. Photodiagnosis and Photodynamic Therapy, 25, 253-258. https://doi.org/10.1016/j. pdpdt.2019.01.004

13. Shen, J. J., Jemec, G. B. E., Arendrup, M. C., \& Saunte, D. M. L. (2020). Photodynamic therapy treatment of superficial fungal infections: a systematic review. Photodiagnosis and Photodynamic Therapy, 31, 101774. https://doi.org/10.1016/j.pdpdt.2020. 101774

14. Hu, J. J., Lei, Q., \& Zhang, X. Z. (2020). Recent advances in photonanomedicines for enhanced cancer photodynamic therapy. Progress in Materials Science, 114, 100685. https://doi.org/10. 1016/j.pmatsci.2020.100685

15. D'Alessandro, S., \& Priefer, R. (2020). Non-porphyrin dyes used as photosensitizers in photodynamic therapy. Journal of Drug Delivery Science and Technology, 60, 101979. https://doi.org/10. 1016/j.jddst.2020.101979

16. Yi, C., Yu, Z., Ren, Q., Liu, X., Wang, Y., Sun, X., et al. (2020). Nanoscale ZnO-based photosensitizers for photodynamic therapy. Photodiagnosis and Photodynamic Therapy, 30, 101694. https:// doi.org/10.1016/j.pdpdt.2020.101694

17. Gao, D., Gao, Y., Shen, J., \& Wang, Q. (2020). Modified nanoscale metal organic framework-based nanoplatforms in photodynamic therapy and further applications. Photodiagnosis and Photodynamic Therapy, 32, 102026. https://doi.org/10.1016/j. pdpdt.2020.102026

18. Tian, J., Huang, B., Nawaz, M. H., \& Zhang, W. (2020). Recent advances of multidimensional porphyrin-based functional materials in photodynamic therapy. Coordination Chemistry Reviews, 420, 213410. https://doi.org/10.1016/j.ccr.2020.213410

19. Kwiatkowski, S., Knap, B., Przystupski, D., Saczko, J., Kędzierska, E., Knap-Czop, K., et al. (2018). Photodynamic therapy-mechanisms, photosensitizers and combinations. Biomedicine and Pharmacotherapy, 106, 1098-1107. https://doi.org/ 10.1016/j.biopha.2018.07.049

20. Allison, R. R., \& Moghissi, K. (2013). Oncologic photodynamic therapy: clinical strategies that modulate mechanisms of action. Photodiagnosis and Photodynamic Therapy, 10, 331-341. https:// doi.org/10.1016/j.pdpdt.2013.03.011

21. Vittar, N. B. R., Comini, L., Fernadez, I. M., Agostini, E., NuñezMontoya, S., Cabrera, J. L., et al. (2014). Photochemotherapy using natural anthraquinones: rubiadin and soranjidiol sensitize human cancer cell to die by apoptosis. Photodiagnosis and Photodynamic Therapy, 11, 182-192. https://doi.org/10.1016/j.pdpdt. 2014.02.002

22. Rajendran, M. (2016). Quinones as photosensitizer for photodynamic therapy: ROS generation, mechanism and detection methods. Photodiagnosis and Photodynamic Therapy, 13, 175-187. https://doi.org/10.1016/j.pdpdt.2015.07.177

23. Brandão, M. G. L., Grandi, T. S. M., Rocha, E. M. M., Sawyer, D. R., \& Krettli, A. U. (1992). Survey of medicinal plants used as antimalarials in the Amazon. Journal of Ethnopharmacology, 36, 175-182. https://doi.org/10.1016/0378-8741(92)90018-M

24. Nunes, L. G., Gontijo, D. C., Souza, C. J. A., Fietto, L. G., Carvalho, A. F., \& Leite, J. P. V. (2012). The mutagenic, DNA-damaging and antioxidative properties of bark and leaf extracts from Coutarea hexandra (Jacq.) K. Schum. Environmental Toxicology and Pharmacology, 33, 297-303. https://doi.org/10.1016/j.etap. 2011.12.003

25. Gholibegloo, E., Karbasi, A., Pourhajibagher, M., Chiniforush, N., Ramazani, A., Akbari, T., et al. (2018). Carnosine-graphene oxide conjugates decorated with hydroxyapatite as promising nanocarrier for ICG loading with enhanced antibacterial effects in photodynamic therapy against Streptococcus mutans. Journal of Photochemistry and Photobiology B: Biology, 181, 14-22. https:// doi.org/10.1016/j.jphotobiol.2018.02.004
26. Juybar, M., Khorrami, M. K., \& Bagheri, G. A. (2020). FTIR/ PLS and SVM multivariate calibrations to determination of the coke amount into the deactivated catalysts and the product of the methanol to gasoline conversion. Infrared Physics and Technology, 105, 103229. https://doi.org/10.1016/j.infrared.2020.103229

27. Aboulwafa, M. M., Youssef, F. S., Gad, H. A., Sarker, S. D., Nahar, L., Al-Azizi, M. M., et al. (2019). Authentication and discrimination of green tea samples using UV-vis, FTIR and HPLC techniques coupled with chemometrics analysis. Journal of Pharmaceutical and Biomedical Analysis, 164, 653-658. https://doi. org/10.1016/j.jpba.2018.11.036

28. Kumar, R., \& Sharma, V. (2017). A novel combined approach of diffuse reflectance UV-Vis-NIR spectroscopy and multivariate analysis for non-destructive examination of blue ballpoint pen inks in forensic application. Spectrochimica Acta-Part A: Molecular and Biomolecular Spectroscopy, 175, 67-75. https://doi.org/10. 1016/j.saa.2016.12.008

29. Riswahyuli, Y., Rohman, A., Setyabudi, F. M. C. S., \& Raharjo, S. (2020). Indonesian wild honey authenticity analysis using attenuated total reflectance-Fourier transform infrared (ATR-FTIR) spectroscopy combined with multivariate statistical techniques. Heliyon, 6, e03662. https://doi.org/10.1016/j.heliyon.2020.e03662

30. Tarhan, İ, \& Işık, İ. (2020). An in-depth chemometric study: archaeometric characterization of ceramic shards excavated from the sanctuary of Hecate at Lagina in Muğla (Turkey) by FTIR spectroscopy and multivariate data analysis. Vibrational Spectroscopy, 111, 103172. https://doi.org/10.1016/j.vibspec.2020.103172

31. Lin, J., Chen, H., Li, S., Liu, Y., Li, X., \& Yu, B. (2019). Accurate prediction of potential druggable proteins based on genetic algorithm and bagging-SVM ensemble classifier. Artificial Intelligence in Medicine, 98, 35-47. https://doi.org/10.1016/j.artmed.2019.07. 005

32. Cooke, B., \& Schmidler, S. C. (2008). Statistical prediction and molecular dynamics simulation. Biophysical Journal, 95, 4497 4511. https://doi.org/10.1529/biophysj.108.131623

33. Villalba, P., Sanchis, J., \& Ferrer, A. (2019). A graphical user interface for PCA-based MSPC: a benchmark software for multivariate statistical process control in MATLAB. Chemometrics and Intelligent Laboratory Systems, 185, 135-152. https://doi.org/10. 1016/j.chemolab.2018.12.004

34. Kim, Y. M., MacGregor, J. F., \& Kostanski, L. K. (2005). Principal component analysis of FT-IR spectra for cationic photopolymerization of mixtures of two monomers. Chemometrics and Intelligent Laboratory Systems, 75, 77-90. https://doi.org/10. 1016/j.chemolab.2004.05.009

35. Stanimirova, I., Walczak, B., Massart, D. L., \& Simeonov, V. (2004). A comparison between two robust PCA algorithms. Chemometrics and Intelligent Laboratory Systems, 71, 83-95. https:// doi.org/10.1016/j.chemolab.2003.12.011

36. Bacci, M., Chiari, R., Porcinai, S., \& Radicati, B. (1997). Principal component analysis of near-infrared spectra of alteration products in calcareous samples: an application to works of art. Chemometrics and Intelligent Laboratory Systems, 39, 115-121. https://doi.org/10.1016/S0169-7439(97)00063-4

37. Cooper, J. B. (1999). Chemometric analysis of Raman spectroscopic data for process control applications. Chemometrics and Intelligent Laboratory Systems, 46, 231-247. https://doi.org/10. 1016/S0169-7439(98)00174-9

38. Rousseau, R., Govaerts, B., Verleysen, M., \& Boulanger, B. (2008). Comparison of some chemometric tools for metabonomics biomarker identification. Chemometrics and Intelligent Laboratory Systems, 91, 54-66. https://doi.org/10.1016/j.chemolab.2007. 06.008

39. Sun, L. X., Xu, F., Liang, Y. Z., Xie, Y. L., \& Yu, R. Q. (1994). Cluster analysis by the K-means algorithm and simulated 
annealing. Chemometrics and Intelligent Laboratory Systems, 25, 51-60. https://doi.org/10.1016/0169-7439(94)00049-2

40. Andrada, M. F., Vega-Hissi, E. G., Estrada, M. R., \& Garro Martinez, J. C. (2015). Application of k-means clustering, linear discriminant analysis and multivariate linear regression for the development of a predictive QSAR model on 5-lipoxygenase inhibitors. Chemometrics and Intelligent Laboratory Systems, 143, 122-129. https://doi.org/10.1016/j.chemolab.2015.03.001

41. Cai, P., \& Deng, X. (2020). Incipient fault detection for nonlinear processes based on dynamic multi-block probability related kernel principal component analysis. ISA Transactions, 105, 210-220. https://doi.org/10.1016/j.isatra.2020.05.029

42. Peng, C., Zhang, Q., Kang, Z., Chen, C., \& Cheng, Q. (2020). Kernel two-dimensional ridge regression for subspace clustering. Pattern Recognition. https://doi.org/10.1016/j.patcog.2020. 107749

43. Zhou, T., \& Peng, Y. (2020). Kernel principal component analysis-based Gaussian process regression modelling for highdimensional reliability analysis. Computers and Structures, 241, 106358. https://doi.org/10.1016/j.compstruc.2020.106358

44. dos Santos, P. L., \& Perdicoúlis, T. P. A. (2019). A kernel principal component regressor for LPV system identification. IFACPapersOnLine, 52, 7-12. https://doi.org/10.1016/j.ifacol.2019.12. 339

45. Ni, T., Qiao, M., Chen, Z., Zhang, S., \& Zhong, H. (2020). Utilityefficient differentially private K-means clustering based on cluster merging. Neurocomputing. https://doi.org/10.1016/j.neucom. 2020.10 .051
46. Jolliffe, I. T. (1986). Principal components in regression analysis (pp. 129-155). Springer. https://doi.org/10.1007/ 978-1-4757-1904-8_8

47. Jolliffe, I. T., Trendafilov, N. T., \& Uddin, M. (2003). A Modified principal component technique based on the LASSO. Journal of Computational and Graphical Statistics, 12, 531-547. https://doi. org/10.1198/1061860032148

48. Gong, W., Cheng, F., Rolls, E. T., Lo, C. Y. Z., Huang, C. C., Tsai, S. J., et al. (2019). A powerful and efficient multivariate approach for voxel-level connectome-wide association studies. NeuroImage, 188, 628-641. https://doi.org/10.1016/j.neuroimage.2018.12.032

49. Zhang, L., Zheng, Y., Wang, K., Zhang, X., \& Zheng, Y. (2014). An optimized Nash nonlinear grey Bernoulli model based on particle swarm optimization and its application in prediction for the incidence of hepatitis B in Xinjiang, China. Computers in Biology and Medicine, 49, 67-73. https://doi.org/10.1016/j.compbiomed. 2014.02.008

50. Ethirajan, M., Chen, Y., Joshi, P., \& Pandey, R. K. (2011). The role of porphyrin chemistry in tumor imaging and photodynamic therapy. Chemical Society Reviews, 40, 340-362. https://doi.org/ 10.1039/b915149b

51. Bhawalkar, J. D., Kumar, N. D., Zhao, C.-F., \& Prasad, P. N. (1997). Two-photon photodynamic therapy. Journal of Clinical Laser Medicine \& Surgery, 15, 201-204. https://doi.org/10.1089/ clm.1997.15.201 